Istem Özen has a BA and MA in chemical engineering, $\mathrm{PhD}$ in material science and engineering, post-doctoral research at Eletrra Sincrotrone Trieste and Tasc National Laboratory. Inquires the limits to how much the concepts and methods in basic sciences can diffuse into social sciences and arts (and vice versa), aiming for a continuum encompassing all. Writes, looks closely at things in very small and very large dimensions, collects images, translates, acts, teaches, learns.

\title{
In Awe of the Portal
}

Electron micro-graph installation, 2019

Beam me down! I want to have a walk in nature, dive in, shrink down there-tens of thousands of times-and be in awe of it all. Samples are imperfect, broken, detached. Experiment failed. Time's up, but no place for disheartening: one's unworthy data is another one's wonderland. Inadvertently mesmerising. Not valuable yet priceless. Now, have a good look: granted it's always there, yet is not always to be found. Just look. And let the indistinctive reveal its treasure.
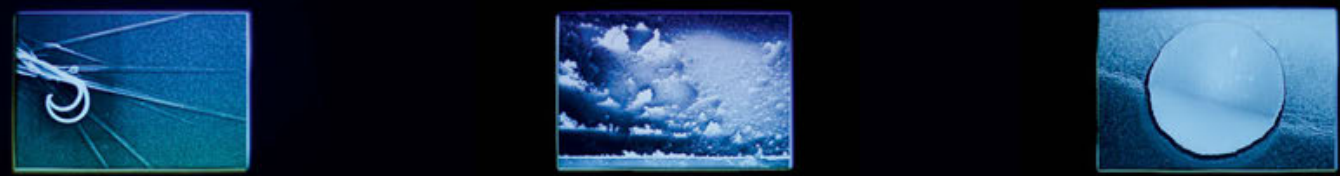


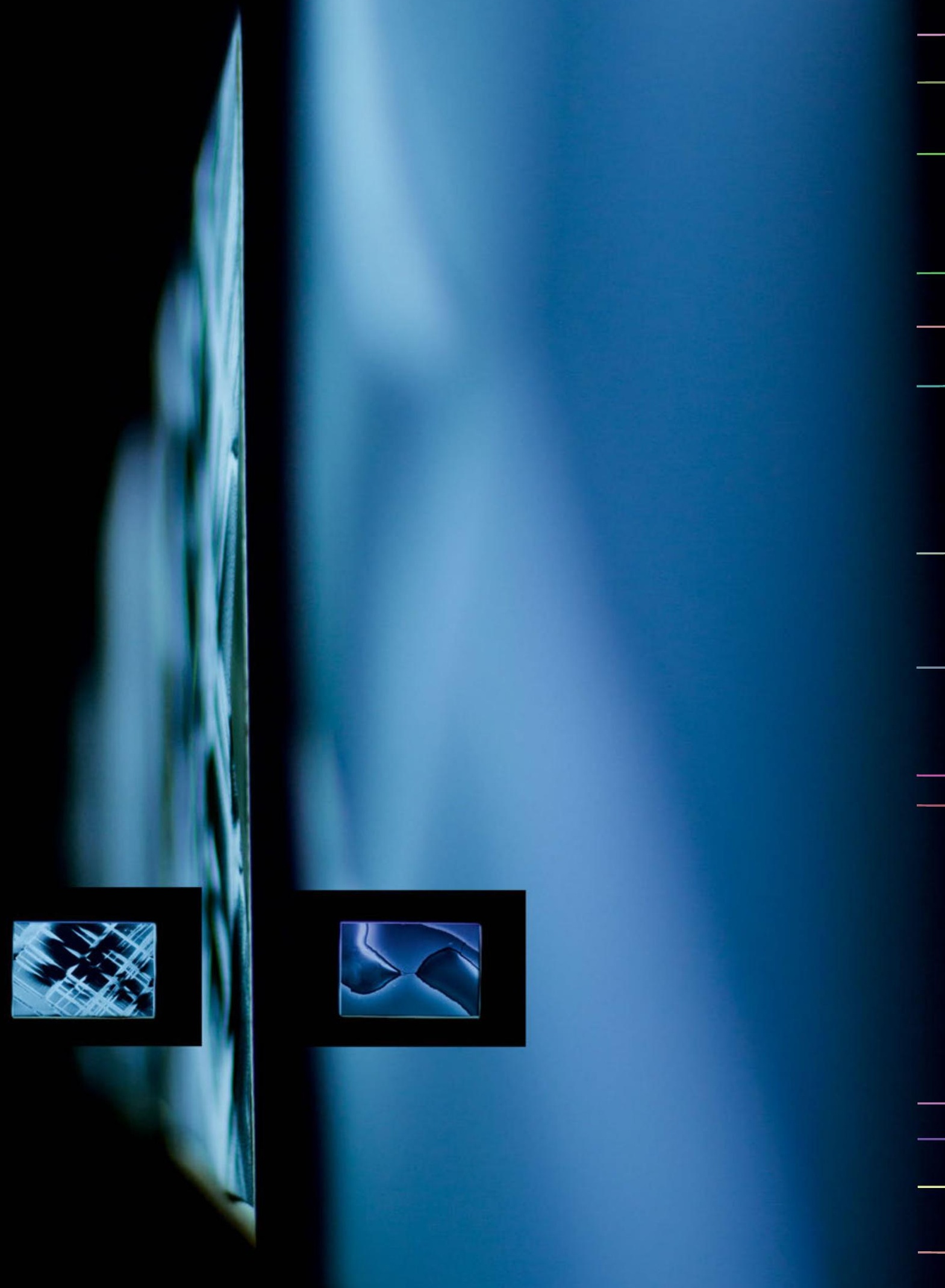



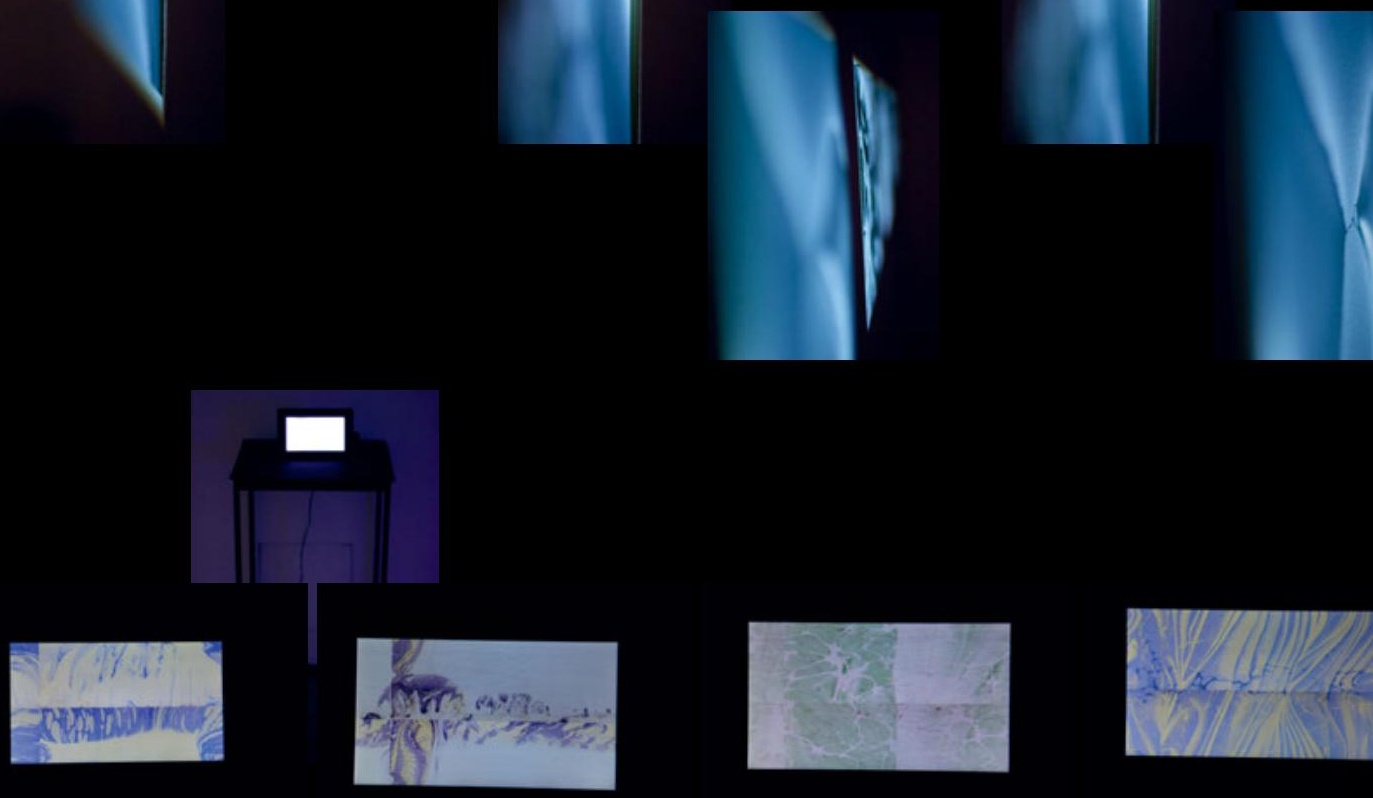

\section{$\stackrel{-\cdots}{=-1}$}
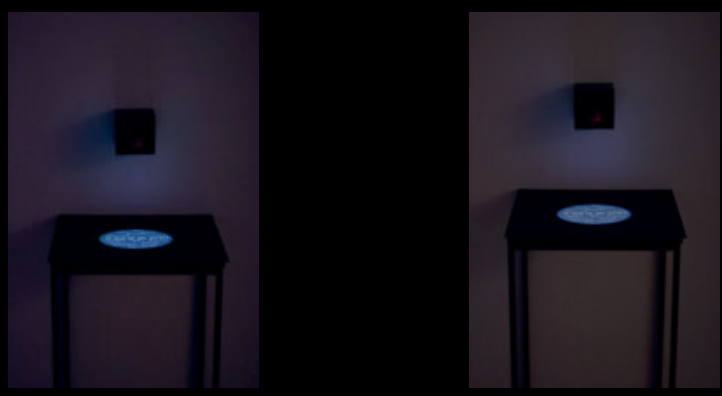

近

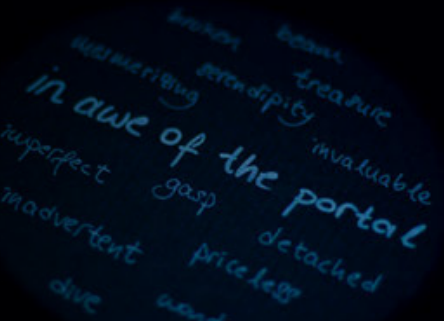

in awe of the portal

mperpete garp detached

modvectront prokes

ane 

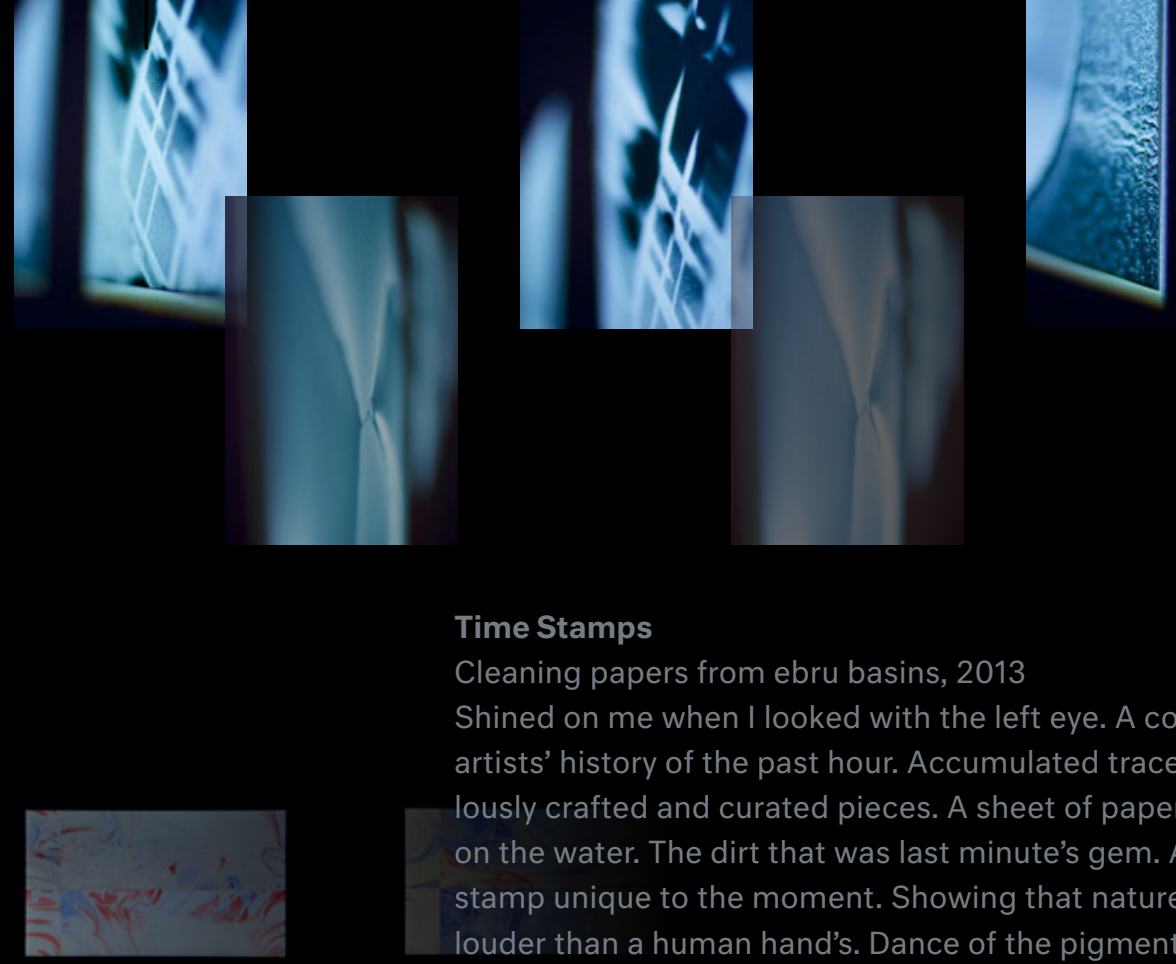

\section{Time Stamps}

Cleaning papers from ebru basins, 2013

Shined on me when I looked with the left eye. A compilation of the artists' history of the past hour. Accumulated traces of many meticulously crafted and curated pieces. A sheet of paper to wipe the dirt on the water. The dirt that was last minute's gem. A collective time stamp unique to the moment. Showing that nature's voice can be louder than a human hand's. Dance of the pigments, and the stories that they tell: it's physics, chemistry, and a human touch for a moment in time.
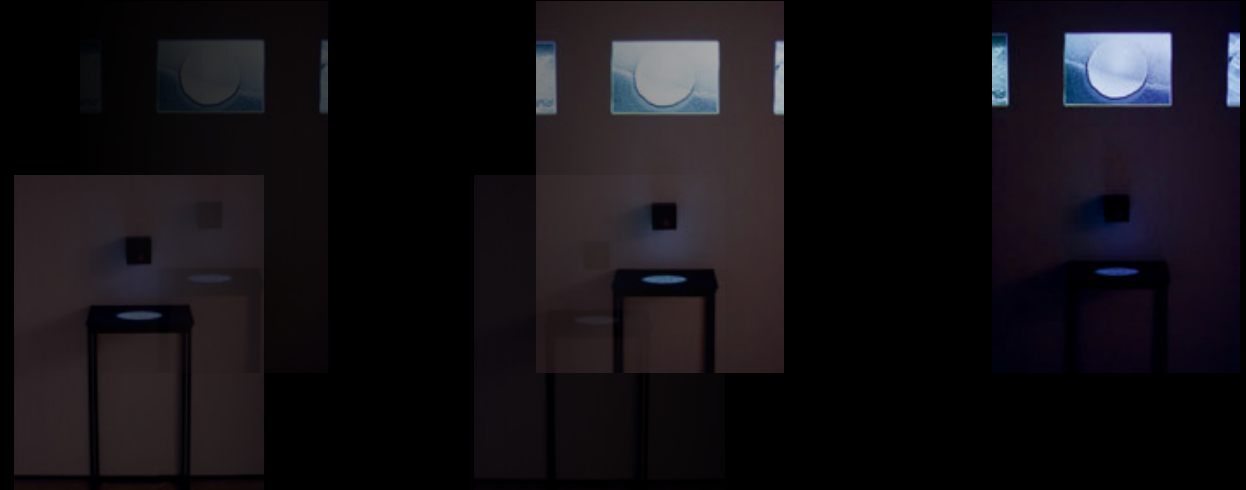